\title{
Status and costs of smoking cessation in countries of the Eastern Mediterranean Region
}

\author{
G. Heydari, ${ }^{7}$ F. Talischi, ${ }^{2}$ N. Mojgani, ${ }^{3}$ M.R. Masjedi, ${ }^{2}$ H. Algouhmani, ${ }^{4}$ H.A. Lando ${ }^{5}$ and A. Ebn Ahmady ${ }^{6}$
}

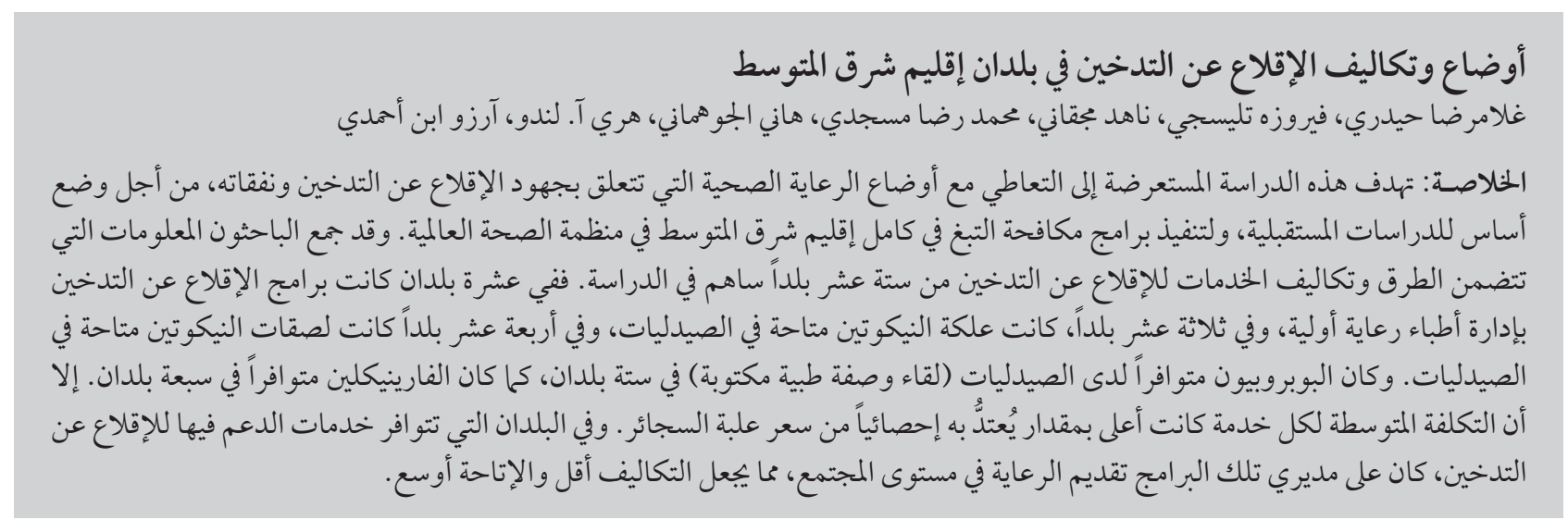

ABSTRACT The aim of this cross-sectional observational study was to address the health care situation in regard to smoking cessation efforts and expenditure, and to provide a basis for future studies and for implementing tobacco control programmes throughout the Eastern Mediterranean Region of the World Health Organization. Information collected included methods and cost of services for tobacco cessation from all 16 participating countries. In 10 countries, cessation programmes were directed by primary physicians. In 13 countries, nicotine gum and in 14 countries nicotine patches were accessible in pharmacies. Bupropion was available at pharmacies (with a written prescription) in 6 countries and varenicline in 7 countries. However, the mean cost of each service was significantly higher than the price of a pack of cigarettes. In countries with support services for tobacco cessation, directors need to provide care at the society level that is considerably less costly and widely accessible.

\section{Situation et coûts du sevrage tabagique dans les pays de la Région de la Méditerranée orientale}

RÉSUMÉ La présente étude d'observation transversale visait à analyser la situation des soins de santé en termes d'efforts de sevrage tabagique et de dépenses dans ce domaine, et à fournir des données de référence pour les études ultérieures et pour la mise en ouvre de programmes de lutte antitabac dans l'ensemble de la Région de la Méditerranée orientale de l'Organisation mondiale de la Santé. Les informations recueillies portaient sur les méthodes et les coûts des services de sevrage tabagique dans les 16 pays participants. Dans dix pays, les programmes de sevrage tabagique étaient dirigés par des médecins de soins de santé primaires. Les gommes et les timbres à base de nicotine étaient disponibles en pharmacie dans 13 et 14 pays respectivement. Le Bupropion était disponible en pharmacie (sur ordonnance) dans six pays et la varénicline dans sept pays. Toutefois, le coût moyen de chaque service était significativement supérieur au prix d'un paquet de cigarettes. Dans les pays dotés de services d'aide au sevrage tabagique, les directeurs doivent fournir des soins au niveau de la société qui soient bien moins onéreux et largement accessibles.

${ }^{1}$ Tobacco Prevention and Control Research Centre, Masih Daneshvari Hospital; ${ }^{2}$ National Research Institute of Tuberculosis and lung Disease ${ }^{6}$ Community Oral Health Department, School of Dentistry, Shahid Beheshti University of Medical Sciences, Tehran, Islamic Republic of Iran (Correspondence to A. EbnAhmady: a.ebnahmady@sbmu.ac.iroraebnahmady@yahoo.com).

${ }^{3}$ Razi Vaccine Serum \& Research Institute, Karaj, Islamic Republic of Iran.

${ }^{4}$ Framework Convention Alliance, Geneva, Switzerland.

${ }^{5}$ Division of Epidemiology and Community Health, School of Public Health, University of Minnesota, Minneapolis, Minnesota, United States of America.

Received: 03/08/11; accepted: 04/10/11 


\section{Introduction}

Tobacco kills nearly 6 million people and causes hundreds of billions of dollars of economic damage worldwide each year [1]. More than $80 \%$ of the world's tobacco-related deaths will be in low and middle-income countries by 2030 [2].

Most smokers who are aware of the dangers of tobacco want to quit, but quitting without assistance is difficult because nicotine is highly addictive [1]. Unfortunately, for individuals who are addicted to any substance, quitting is difficult. Yet, support in quitting can substantially increase the likelihood of cessation and individuals can be aided to overcome their addiction.

Including tobacco cessation in primary health care as part of regular medical visits is a low-cost strategy that provides opportunity to increase awareness of tobacco harms and to encourage quitting. Repeated advice at each visit can emphasize the importance of tobacco cessation and increase the likelihood that patients will quit $[2,3]$. Additionally, counselling by health workers may increase quit rates [4]. Counselling by health workers other than physicians can be relatively inexpensive and can be made available to most individuals. These interventions presented by health professionals tend to have good credibility and to be accepted by tobacco consumers $[5,6]$.

In addition to physician recommendations, effective treatment may also include medications. Available medications include nicotine replacement in the form of skin patches, lozenges, gum, nasal spray and prescription medications including bupropion, an antidepressant that helps by decreasing the craving, and varenicline, a medication which binds to nicotine receptors in the brain and prevents dopamine release, thus decreasing the pleasure of smoking [7]. These medications are frequently available at pharmacies with or without a prescription [4].

Medication is usually more costly than physician advice and phone counselling, but it can double or even triple success rates for quitting [8]. The cost for nicotine replacement can be less than the cost of the tobacco that would have been consumed during the same period of time. It was only over the 5 years from early 2000 onwards that New Zealand offered comprehensive cessation services; it is now one of the most advanced countries in the world in this respect [5].

Since countries in the World Health Organization (WHO) Eastern Mediterranean Region (EMR) including the Middle East and North Africa are mostly low- and middle-income countries, providing resources for tobacco cessation is challenging. This is especially unfortunate given the often high levels of cigarette consumption and aggressive promotion by tobacco companies. Under these circumstances the need for comprehensive tobacco cessation programmes at national and Regional levels becomes especially evident.

Up to now, there has been little information on comparative costs of smoking cessation and continuing smoking in low- and middle-income countries. The aim of this study was, therefore, to identify smoking cessation programmes and smoking status in the Region to provide the basis for future studies on tobacco cessation programmes in these countries.

\section{Methods}

This cross-sectional observational study was planned following a meeting of a committee of the Intergovernmental Negotiating Body 3 (INB3) in July 2009 in Geneva, Switzerland. Representatives of all 16 participating countries in the EMR, all of whom were focal points or experts in tobacco control, were requested to respond to a questionnaire which collected data on the costs of smoking cessation services. The response rate was $100 \%$.

Information was collected using a checklist which was developed by an expert group in the WHO-EMR collaborating centre on tobacco control. The checklist included items assessing methods for tobacco cessation and cost of services including counselling by primary physician or specialist, gum or nicotine patches, bupropion, varenicline, etc.

Other information collected included the price of cigarettes and accessibility of tobacco cessation programmes based on previously published country reports [9]. This information covered all 21 EMR countries studied.

The data were analysed using SPSS, version 9 . Frequency and mean were determined as well as standard deviation (SD).

\section{Results}

The information regarding the cost of smoking cessation programmes collected from 21 Eastern Mediterranean countries is shown in Table 1. In 10 countries tobacco cessation programmes and counselling were performed by general practitioners. Additionally, 8 countries provided these programmes through specialists. In 10 countries, however, no general practitioner counselling service was available.

In 13 countries, nicotine gum and in 14 , nicotine patch were available at pharmacies. In 6 countries bupropion pills $(150 \mathrm{mg}$ ) and in 7 countries Varenicline were available at pharmacies on prescription.

The representatives of the $16 \mathrm{EMR}$ countries participating in the INBR3 meeting were also asked about the availability of a telephone help line for quitting smoking; the only country which 


\begin{tabular}{|c|c|c|c|c|c|c|c|c|}
\hline \multirow[t]{3}{*}{ Country } & \multicolumn{8}{|c|}{ Cost (US\$) } \\
\hline & \multicolumn{2}{|c|}{ Counselling ${ }^{\mathrm{a}}$} & \multicolumn{2}{|c|}{$\begin{array}{l}\text { Nicotine } \\
\text { replacement }\end{array}$} & \multirow[t]{2}{*}{ Bupropion $^{b}$} & \multirow[t]{2}{*}{ Varenicline $^{\mathrm{c}}$} & \multicolumn{2}{|c|}{ Pack of cigarettes } \\
\hline & $\mathbf{G P}^{\mathbf{d}}$ & Specialist & Gum ${ }^{\mathrm{e}}$ & Patch $^{\mathrm{f}}$ & & & Marlboro & Domestic \\
\hline Afghanistan & - & - & - & - & - & - & 0.4 & 0.4 \\
\hline Bahrain & - & 12 & 1.5 & 4 & 2.6 & 2 & 1.4 & - \\
\hline Djibouti & - & - & 2 & 8 & 2 & 3 & - & - \\
\hline Egypt & 15 & 20 & 2.5 & 1.5 & 2 & 7 & 1.3 & 1.2 \\
\hline $\operatorname{Iran}(I R)$ & 3 & 10 & 3 & 7 & 2 & 3 & 1.8 & 0.4 \\
\hline Iraq & - & - & 2 & 5 & - & - & 1.5 & 1 \\
\hline Jordan & - & - & 2.5 & 6 & - & - & 2.1 & 0.7 \\
\hline Kuwait & 4 & 15 & 4 & 8 & - & - & 1.6 & 3 \\
\hline Lebanon & 5 & 10 & 2 & 6 & 2 & 3 & 1.4 & 1.6 \\
\hline Libya & - & - & - & - & - & - & 1.7 & 1.4 \\
\hline Morocco & 5 & 10 & 3 & 6 & 2.5 & 2.5 & 3.9 & 1.8 \\
\hline Oman & - & - & 3 & 6 & - & - & 1.8 & 1.5 \\
\hline Pakistan & - & - & - & - & - & - & 1.1 & 0.8 \\
\hline Qatar & 5 & - & 2 & 7 & - & - & 1.3 & 1.3 \\
\hline Saudi Arabia & - & - & - & - & - & - & 1.5 & 3 \\
\hline Somalia & - & - & - & - & - & - & - & - \\
\hline Sudan & 7 & 25 & - & - & - & - & 2.4 & 0.9 \\
\hline $\begin{array}{l}\text { Syrian Arab } \\
\text { Republic }\end{array}$ & 4 & - & - & 2.3 & - & 2.5 & 1.5 & 0.6 \\
\hline Tunisia & 3 & 10 & 2 & 5 & - & - & 2.5 & 0.8 \\
\hline UAE & - & - & 3 & 8 & - & - & 1.6 & 1.4 \\
\hline Yemen & 5 & - & - & - & - & - & 0.8 & 0.8 \\
\hline
\end{tabular}

${ }^{a}$ One visit and counselling session. ${ }^{b}$ Two pills of $150 \mathrm{mg}$ each for daily use. ${ }^{c}$ Two pills of $1 \mathrm{mg}$ for daily use. ${ }^{d}$ Primary care physician. ${ }^{e}$ Use of 8 gums a day. ${ }^{f}$ One patch for daily use.

$-=$ data not available at the time of the study.

$G P=$ general practitioner $; U A E=$ United Arab Emirates.

mentioned having a quit line was the Islamic Republic of Iran.

The mean cost of a consultation provided in 1 specialist visit (US\$ 14.6; SD 5.6) was about 7 times higher than the mean daily cost of bupropion (US\$ 2.1; SD 0.2) treatment and treatment with nicotine gum (US\$ 2.5; SD 0.6) (Table 2). It is clear that the cost of various cessation methods substantially exceeds the cost of a pack of cigarettes (Table 2).

\section{Discussion}

Programmes for tobacco cessation are considered critical for tobacco control in society [10]. The World Health Organization recommendation bringing in MPOWER emphasized providing cessation programmes in the countries [11].As stated in Article 14 of the World Health Organization Framework Convention on Tobacco Control, which was adopted at the Conference of the Parties to the Framework, countries are responsible for the provision of smoking cessation services at the national level [12].

In the EMR countries as well as in the countries of the WHO Africa Region and the South-East Asia Region, the proportion of smoking cessation services was limited in comparison with countries in the other WHO Regions.
The Eastern Mediterranean Region countries, which have large smoking populations and a high prevalence of tobacco consumption promoted by tobacco industry marketing, do not have readily-available and affordable cessation services and medications commensurate with the scope of the problem [11]. As evident in our results, about half of the countries we studied do not have counselling services by physicians. This number is substantially lower than in other WHO Regions, including the European Region (90\%), the Region of the Americas 80\%, South-East Asia Region and Western Pacific Region 70\% [11]. Increased attention and resources are needed to 


\begin{tabular}{|c|c|c|c|c|}
\hline \multirow[t]{2}{*}{ Variable } & \multirow[t]{2}{*}{ Availability ${ }^{a}$} & \multicolumn{3}{|c|}{ Cost (US\$) } \\
\hline & & Minimum & Maximum & Mean (SD) \\
\hline \multicolumn{5}{|l|}{ Measure } \\
\hline GP visit & 11 & 3 & 15 & $5.8(3.4)$ \\
\hline Specialist visit & 9 & 10 & 25 & $14.6(5.6)$ \\
\hline Daily nicotine gum & 13 & 1.5 & 4 & $2.5(0.6)$ \\
\hline Daily nicotine patch & 14 & 1.5 & 8 & $5.7(2.0)$ \\
\hline Daily bupropion & 6 & 2 & 2.6 & $2.1(0.2)$ \\
\hline Daily varenicline & 7 & 2 & 7 & $3.2(1.6)$ \\
\hline \multicolumn{5}{|l|}{ Cigarettes (pack) } \\
\hline Marlboro & 19 & 0.40 & 3.9 & $1.6(0.7)$ \\
\hline Domestic & 18 & 0.40 & 3.0 & $1.2(0.7)$ \\
\hline
\end{tabular}

${ }^{a}$ Number of countries in which these services are available. $G P=$ general practitioner . $S D=$ standard deviation .

address this lack of services in the EMR. The same is true regarding access to nicotine-containing medication. These medications are accessible in most European, American, South-East Asian and Western Pacific countries [13] but it was not available in one-third of the EMR countries.

Additionally, accessibility of nonnicotine-containing medications, including bupropion and varenicline, is extremely low. This is in contrast to the fargreater access to these medications in some other WHO Regions, e.g. North America [4]. Again, more attention is needed to improve access to cessation programmes, including medications, in the EMR Region.

Unfortunately, the high cost of cessation services relative to the cost of continued smoking (quitting costs are 2-9 times greater than daily cigarette consumption) may discourage the use of these services and have an adverse impact on quit rates. In countries where the cost of cigarettes is considerably higher there may be more comparability between the price of cigarettes and the cost of cessation services $[4,8]$. Research is needed on the impact of cost on accessing cessation services.

Furthermore, in addition to limitations imposed by cost, the availability of cessation programmes in the countries of the Region is limited. It should be noted that prices vary across brands and can also vary within a country. Therefore these comparisons are not absolute, but they do provide an indication of the overall low price of cigarettes compared with the cost of cessation services.

Recall bias could be considered a threat to the internal validity of a study given that data are often self-reported. In order to avoid or minimize this bias in our study we considered the tobacco control focal points (individuals who are active in this field) in each country as the source for reporting data.

\section{Conclusions}

In EMR countries where cessation services are provided, these services should be made affordable and accessible at the community level. Countries that have not participated in these efforts should consider plans for disseminating effective and affordable cessation treatment. Also much more needs to be done to ensure services for tobacco cessation at the countrylevel are low cost and widely accessible. In countries where no such services exist, it is imperative that initiatives to provide these services begin as soon as possible.

\section{Acknowledgements}

The authors are grateful to all representatives of the countries present at the INB3 meeting for the protocol on tobacco smuggling as part of the Framework Convention on Tobacco Control and to colleagues at the Framework Convention Alliance for the provision of information reported in this article.

\section{References}

1. WHO Report on the Global Tobacco Epidemic, 2011: warning about the dangers of tobacco. Geneva, World Health Organization, 2011 (www.who.int/tobacco/global_report/2011/en/ index.html, accessed 16 September 2012).
2. Solberg LI et al. Repeated tobacco-use screening and intervention in clinical practice: health impact and cost effectiveness. American Journal of Preventive Medicine, 2006, 31(1):62-71. 
3. West R, Sohal T. Catastrophic pathways to smoking cessation: findings from national survey. British Medical Journal, 2006 , 332(7539):458-460.

4. Fiore MC. Treating tobacco use and dependence: a public health service clinical practice guideline. Rockville, Maryland, US Department of Health and Human Services (press briefing) (http://www.askadviserefer.org/downloads/clinicalPracticeGuidelines.pdf, accessed 25 September 2012).

5. Feenstra TL et al. Cost-effectiveness of face-to-face smoking cessation interventions: a dynamic modeling study. Value in Health, 2005, 8(3):178-190.

6. Bao Y, Duan N, Fox SA. Is some provider advice on smoking cessation better than no advice? An instrumental variable analysis of the 2001 National Health Interview Survey. Health Services Research, 2006, 41(6):2114-2135.

7. Garrison G, Dugan S. Varniclin: a first line treatment option foe smoking cessation. Clinical therapeutics, 2009, 31(3):463-491.

8. Nicotine addiction in Britain; a report of the Tobacco Advisory Group of the Royal College of Physicians. London, Royal College of Physicians of London, 2000 (http://bookshop.rcplondon. ac.uk/contents/pub131-2740272e-57b4-4567-b87c-cda5ef7cd7e0.pdf, accessed 18 September 2012).

9. Shafey $\mathrm{O}$ et al. The tobacco atlas, 3rd ed. Atlanta, Georgia, American Cancer Society and World Lung Foundation, 2009.

10. Hendricks PS et al. The early time course of smoking withdrawal effects. Psychopharmacology, 2006, 187(3):385-396.

11. WHO Report on the Global Tobacco Epidemic: the MPOWER package. Geneva, World Health Organization, 2008.

12. Conference of the Parties to the WHO Framework Convention on Tobacco Control. First report of Committee A. Geneva, World Health Organization, 2007 [(Draft) A/FCTC/COP/2/17] (http://www.who.int/gb/fctc/PDF/cop2/FCTC_COP2_17P_ en.pdf, accessed 18 September 2012).

13. Breslau N, Peterson EL. Smoking cessation in young adults: age at initiation of cigarette smoking and other suspected influences. American Journal of Public Health, 1996, 86(2):214220

\section{Report on the scientific basis of tobacco product regulation: Fourth report of a WHO Study Group}

This report presents the conclusions reached and recommendations made by the members of the WHO Study Group on Tobacco Product Regulation at its sixth meeting, during which it reviewed two background papers specially commissioned for the meeting and which dealt, respectively, with the following two themes:

1. toxic elements in tobacco and in cigarette smoke

2. the basis for a regulatory framework to reduce the dependence potential of tobacco products.

The Study Group's recommendations in relation to each theme are set out at the end of the section dealing with that theme and its overall recommendations are also later summarized.

Further information about this and other WHO publications is available at: http://www.who.int/publications/en/ 